\title{
Forces Perspective of Drillability of Titanium Alloy 6Al-2Sn-4Zr-6Mo
}

\author{
Mahros Darsin $^{\mathrm{a}}$, Tim Pasang ${ }^{\mathrm{b}}$, Zhan Chen ${ }^{\mathrm{c}}$ \\ ${ }^{a}$ Department of Mechanical Engineering, University of Jember \\ Jalan Kalimantan 37 Jember 68121, Indonesia \\ $+62331410243$ \\ e-mail: mahros.teknik@unej.ac.id \\ ${ }^{b, c}$ Department of Mechanical Engineering, Auckland University of Technology \\ 55 Wellesley Street, Auckland 1010, New Zealand \\ +6499219999 \\ e-mail: timotius.pasang@aut.ac.nz \& zhan.chen@aut.ac.nz
}

\begin{abstract}
This paper concerns on drillability of Ti-6Al-2Sn-4Zr-6Mo (Ti-6246) from the point view of thrust force $(F z)$ \& torque $(\mathrm{Mz})$ using a TiAIN CVD coated carbide tool. The condition of the material was varied with three different heat treatments. Whereas, the machining parameters were varied in cutting speed, feed rate and cooling application method. Taguchi method $L-18$ was employed to design the experiments. Both type of forces, thrust force and torque, were measured using a Kistler dynamometer, and the data were analyzed using a Minitab 17 software. The thrust force was influenced by the cutting speed $24 \%$, depth of drilling $21 \%$, heat treatment $13 \%$, and feed rate $11 \%$. The torque was influenced predominantly by feed rate up to $94 \%$. Coolant application has no effect on reducing both thrust force as well as torque.
\end{abstract}

Keywords: Ti-6246; drillability; Taguchi method; force; torque

\section{INTRODUCTION}

Drillability term is derived from machinability, which means how easy the material be drilled with a drill bit. This paper discusses drillability of titanium alloy $6 \mathrm{Al}-2 \mathrm{Sn}-4 \mathrm{Zr}-6 \mathrm{Mo}$ when being drilled with TiAIN-coated carbide from forces point of view. Cutting forces is a measure of machinability. Normally, it is desired the lower cutting forces. In drilling, an elevated cutting force can arouse the vibration of the spindle axis, consequently resulting in low quality of drilled surface. It may also cause premature devastation of drills and lessen the tool life. An elevated temperature at the interface of tool-workpiece may be produced when the torque was increased due to friction between tool and workpiece [1]. There is a close connection between forces that work during drilling with the surface quality [2]. Therefore, it is interesting to study drillability from the forces point of view.

In drilling, there are two different motions: cutting speed and feed rate. Cutting speed makes the tool cut the workpiece only once of full rotation and feed rate provides the continuity of drilling process. Torque is the force that make the drill able to rotate along vertical axis; it relates to cutting speed. While, thrust force is the force that make the drill move along vertical axis (Z-axis) and it relates to feed rate.

Titanium alloy $6 \mathrm{Al}-2 \mathrm{Sn}-4 \mathrm{Zr}-6 \mathrm{Mo}$ (Ti-6246) is among alpha + beta titanium alloys. It has excellent corrosion ratio than the most famous titanium alloy, Ti-6Al-4V, therefore, it is potentially applied for sea water medium and high chemical influent working area also for deep \& sour-well applications. It is heat treatable and designed to combine the strength properties at long term elevated temperature of Ti-6Al-2Sn-4Zr-2Mo-0.08 Si with the high developed short term strength properties of fully hardened alpha + beta alloy. Hence, it possibly for forging parts which receive withstand high at intermediate temperature such as turbine blades, compressor disks and airframe components. 
Some previous researchers have observed relation of forces that works during machining titanium alloys and the machining parameters. Cutting force $(\mathrm{Fc})$ and feed force (Fk) have been discussed on machining three kind of titanium alloys Ti-6AI4V, Ti-54M and Ti-10.2.3 with variation in machining parameters. They concluded that feed rate was the most influential factor which affects the forces [3]. Laser assisted machining (LAM) has reduced the forces up to maximum $15 \%$ in compare to conventional machining of Ti-6Cr$5 \mathrm{Mo}-5 \mathrm{~V}-4 \mathrm{Al}$ [4]. There is also some published paper on drilling titanium which focus on cutting forces. The main forces that work drilling (thrust force and torque) were greatly affected by the type of coolant used [5,6]. Thrust force decreased as cutting speed increased but a lower torque values were obtained at the higher cutting speed applied [7]. Other researchers concerned on effect of drilling technique on forces as reviewed on Sharif et al. [6]. Literatures studied show that there is no published paper discussing drilliablity of titanium alloy $6 \mathrm{Al}-2 \mathrm{Sn}-4 \mathrm{Zr}-6 \mathrm{Mo}$ especially from forces point view. Therefore, this study worth to value.

\section{Methods}

The material used were titanium alloy 6246 in form of $56 \mathrm{~mm}$ - rod with the nominal chemical composition in compare to the result of OES (optical emission spectroscopy) is presented in Table 2.1.

Table 2.1 Taguchi method $L-18$ design experiments, the forces and $S / R$ ratio

\begin{tabular}{llllllllll}
\hline \multirow{2}{*}{$\begin{array}{c}\text { Work Material Ti- } \\
\text { 6Al-2Sn-4Zr-6Mo }\end{array}$} & \multicolumn{4}{c}{ Alloying elements, } & \multicolumn{5}{c}{ Impurity limits, wt.\% max } \\
\cline { 2 - 11 } & Al & Sn & Zr & Mo & N & C & H & Fe & O \\
\hline From literature [8] & 6 & 2 & 4 & 6 & 0.04 & 0.04 & 0.0125 & 0.15 & 0.15 \\
OES Test Result & 6.69 & 2.18 & 4.09 & 5.85 & & 0.012 & & 0.062 & \\
\hline
\end{tabular}

In advance of drilling, the workpiece was machined to shape rectangular blocks according to the depth of the proposed drilling and to fit with the fixture, width $\mathrm{x}$ length $=25$ $x 25 \mathrm{~mm}$; the heights were varied as 15,35 and $50 \mathrm{~mm}$ according to the proposed depth of drilling 10,30 and $45 \mathrm{~mm}$ respectively. The workpiece was then fastened in a fixture. The fixture itself was mounted on a Kistler piezoelectric dynamometer to measure the forces that worked during drilling. The recorded forces were displayed and recorded in a PC outside the CNC. Four forces were recorded, i.e. Fx, Fy, Fz and Mz.

Five parameters were varied to get the optimum value of forces. Three parameters from drilling ones: cutting force, feed rate, depth of drilling. One variation made from the block being drilled: heat treatments. Another variation came from the environment, i.e. whether drilling with or without coolant. Each variation of parameters has 3 levels except for the coolant application method, only two levels. The experiments were carried out according to Taguchi method L-18 to reduce the number of experiments $[9,10]^{9,10}$. The recorded forces then would be analysed with Minitab 17 and analysis of variance (ANOVA) for checking the significance of each parameters. The variations or level of each parameters is presented in Table 2.2. The initial of AR in heat treatment row means that the material was drilled as-received condition. While HT1 represent heat treatment at $870^{\circ} \mathrm{C}$ for 3 hours following by furnace cooling and $\mathrm{HT} 2$ denotes heat treatment at $870^{\circ} \mathrm{C}$ for 3 hours followed by water quenching. Both heat treatments were chosen based on the preliminary research which result in decreasing the hardness compare to as-received. The value of the hardness of AR, HT1 and HT2 was 318,311 and $289 \mathrm{HV}$ respectively. Lessening the hardness hopefully result in easier to machine. The coolant (coolant 'on') is a synthetic coolant to water ratio 1:10 of HOCUT 795B made by Houghton Australia with flood method at flow rate of $0.02 \mathrm{l} / \mathrm{s}$ through a nozzle. The low and high level of both cutting speed and feed rate were chosen according to the specification of the drill manufacturer for drilling titanium. Hence, the variation of depth of drilling was made because the typical application of this material is for thick parts. The drill insert was denoted as IC908 Sumocham of TiAIN PVD coated carbide. 
Table 2.2 Variation of drilling parameters and their level

\begin{tabular}{lccc}
\hline Machining Parameters & \multicolumn{3}{c}{ Level } \\
\cline { 2 - 4 } & Low & Medium & High \\
\hline Coolant & Off & - & On \\
Heat Treatment & AR & HT1 & HT2 \\
Depth of drilling (mm) & 10 & 30 & 45 \\
Cutting speed (m/min) & 27 & 35 & 50 \\
Feed rate $(\mathrm{mm} / \mathrm{rev})$ & 0.08 & 0.11 & 0.15 \\
\hline
\end{tabular}

\section{RESULTS AND DISCUSSION}

\subsection{Results}

A photo of a moment after drilling showing of the drill and the block as well as the dynamometer is presented in Fig.3.1. The recorded forces (Fx, Fy, Fz and Mz) then being plotted as a graph using Microsoft Excel program. The average of Fx and Fy were around zero value, therefore both were abandoned in further analysis and only Fz (thrust force) and $\mathrm{Mz}$ (torque around the vertical axis) were considered. For analysis in Minitab 17, the forces were sorted out from only at the steady state then take the average as illustrated in Fig. 3.2. The steady state indicating that the tool was fully engage in drilling process [11] 11 . The increase of forces in the graph may relate to tool deterioration.
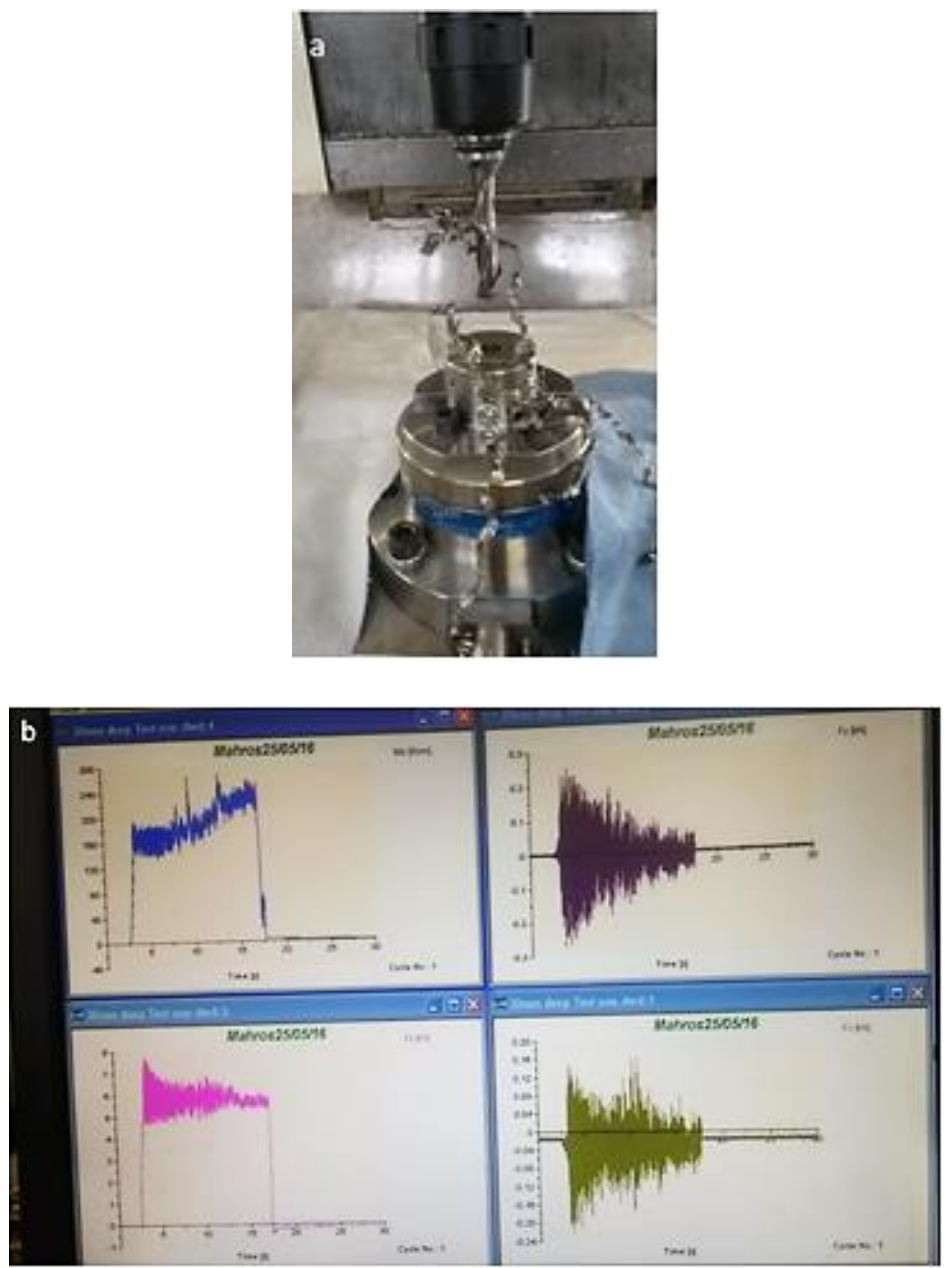

Fig. 3.1 Images showing (a) a moment after a complete drilling, (b) appearance of forces measurement in a PC monitor in the CCW direction from the upper right: $F y, F x, F z$, and Mz 
The completed average of thrust force $(\mathrm{Fz})$ and torque $(\mathrm{Mz})$ is presented in Table 3.1 along the calculated signal to noise ratio ( $\mathrm{S} / \mathrm{N}$ ratio). The calculation of $\mathrm{S} / \mathrm{N}$ ratio was based on minimization because the smaller forces are preferable, as the following formula ${ }^{3}$ :

$$
\left[\frac{S}{N}\right]_{L B}=-10 \log \left(\frac{1}{n} \sum_{n=1}^{n} y_{i}^{2}\right)
$$

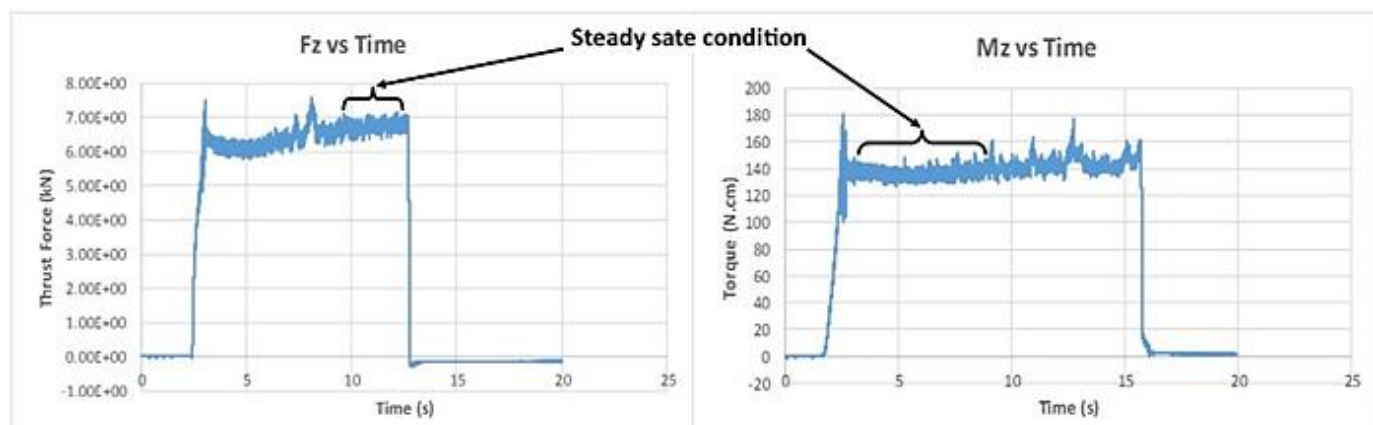

Fig. 3.2. Illustration how the average thrust force and torque were calculated from the steady state condition

Table 3.1 Taguchi method L-18 design experiments, the forces and S/R ratio

\begin{tabular}{|c|c|c|c|c|c|c|c|c|c|}
\hline \multirow[t]{2}{*}{ Exp } & \multicolumn{5}{|c|}{ Control variables } & \multicolumn{2}{|c|}{$\begin{array}{l}\text { Average of } \\
\text { responses }\end{array}$} & \multicolumn{2}{|c|}{$\mathrm{S} / \mathrm{N}$ ratio $(\mathrm{dB})$} \\
\hline & $\begin{array}{l}\text { Coo- } \\
\text { lant }\end{array}$ & HT & $\begin{array}{c}\mathbf{h} \\
(\mathrm{mm})\end{array}$ & $\begin{array}{c}\text { Vc } \\
(\mathrm{m} / \mathrm{min})\end{array}$ & $\begin{array}{c}\text { Fr } \\
(\mathrm{mm} / \mathrm{rev})\end{array}$ & $\begin{array}{l}\mathrm{Fz} \\
(\mathrm{N})\end{array}$ & $\begin{array}{c}\text { Mz } \\
\text { (N.cm) }\end{array}$ & Fz & Mz \\
\hline 1 & No & $\mathrm{AR}$ & 10 & 27 & 0.08 & 2638 & 147 & -68.43 & -43.35 \\
\hline 2 & No & $A R$ & 30 & 35 & 0.11 & 5762 & 165 & -75.21 & -44.33 \\
\hline 3 & No & AR & 45 & 50 & 0.15 & 3567 & 227 & -71.05 & -47.10 \\
\hline 4 & No & HT1 & 10 & 27 & 0.11 & 2679 & 171 & -68.56 & -44.66 \\
\hline 5 & No & HT1 & 30 & 35 & 0.15 & 6701 & 215 & -76.52 & -46.64 \\
\hline 6 & No & HT1 & 45 & 50 & 0.08 & 2234 & 135 & -66.98 & -42.63 \\
\hline 7 & No & HT2 & 10 & 35 & 0.08 & 2245 & 139 & -67.02 & -42.86 \\
\hline 8 & No & HT2 & 30 & 50 & 0.11 & 6761 & 164 & -76.60 & -44.31 \\
\hline 9 & No & HT2 & 45 & 27 & 0.15 & 2744 & 200 & -68.77 & -46.01 \\
\hline 10 & Yes & AR & 10 & 50 & 0.15 & 3895 & 235 & -71.81 & -47.42 \\
\hline 11 & Yes & $A R$ & 30 & 27 & 0.08 & 5256 & 143 & -74.41 & -43.12 \\
\hline 12 & Yes & AR & 45 & 35 & 0.11 & 7231 & 171 & -77.18 & -44.67 \\
\hline 13 & Yes & HT1 & 10 & 35 & 0.15 & 3064 & 210 & -69.73 & -46.44 \\
\hline 14 & Yes & HT1 & 30 & 50 & 0.08 & 2260 & 137 & -67.08 & -42.72 \\
\hline 15 & Yes & HT1 & 45 & 27 & 0.11 & 2735 & 167 & -68.74 & -44.43 \\
\hline 16 & Yes & HT2 & 10 & 50 & 0.11 & 2761 & 180 & -68.82 & -45.11 \\
\hline 17 & Yes & HT2 & 30 & 27 & 0.15 & 2037 & 207 & -66.18 & -46.32 \\
\hline 18 & Yes & HT2 & 45 & 35 & 0.08 & 5225 & 128 & -74.36 & -42.12 \\
\hline
\end{tabular}

\subsection{Discussion}

ANOVA analyses was used to detect which factors affecting the forces. A confidence level $95 \%$ (or significance level of $\alpha=0.05$ ) was used to carry out the critical analysis. The ANOVA of thrust force and torque were presented in Table 3.2 \& Table 3.3. The factor with the P-values less than 0.05 means statistically significant at $95 \%$ confidence level and vice 
versa [3]. Whereas, the larger the F-value for certain parameter the bigger the effect on the characteristic of performance due to change in that process parameter [3].

Table 3.2 Analysis of variance for thrust force

\begin{tabular}{ccccccc}
\hline Source & DF & Adj SS & Adj MS & F-Value & P-Value & $\begin{array}{c}\text { Contribution, } \\
\%\end{array}$ \\
\hline Coolant & 1 & 41762 & 41762 & 0.02 & 0.892 & 0 \\
HT & 2 & 6829219 & 3414609 & 1.62 & 0.257 & 13 \\
h & 2 & 11065125 & 5532562 & 2.62 & 0.133 & 21 \\
Vc & 2 & 13077118 & 6538559 & 3.10 & 0.101 & 24 \\
Fr & 2 & 5823134 & 2911567 & 1.38 & 0.306 & 11 \\
Error & 8 & 16896812 & 2112102 & & & 31 \\
Total & 17 & 53733170 & & & & \\
\hline
\end{tabular}

Table 3.3 Analysis of variance for torque

\begin{tabular}{llccccc}
\hline Source & DF & Adj SS & Adj MS & F-Value & P-Value & $\begin{array}{c}\text { Contribution, } \\
\%\end{array}$ \\
\hline Coolant & 1 & 13.3 & 13.28 & 0.46 & 0.518 & 0 \\
HT & 2 & 446.8 & 223.38 & 7.69 & 0.014 & 2 \\
h & 2 & 315.5 & 157.75 & 5.43 & 0.032 & 2 \\
Vc & 2 & 249.4 & 124.69 & 4.29 & 0.054 & 1 \\
Fr & 2 & 18164.6 & 9082.29 & 312.82 & 0 & 94 \\
Error & 8 & 232.3 & 29.03 & & & 1 \\
Total & 17 & 19421.7 & & & & \\
\hline
\end{tabular}

From Table 3.2 it is clear that each factor contributed in affecting the thrust force in order are $24 \%$ by cutting speed, $21 \%$ by depth of drilling, $13 \%$ by heat treatment and $11 \%$ by feed rate. In contrast, torque was predominantly affected feed rate up to $94 \%$ (Table 3.3). While other machining parameters influence cumulatively about $6 \%$ toward the torque. The result is in accordance with what was found by Khanna in Davim [12] that feed rate contribute $97.2 \%$ on cutting force. Some previous researchers in drilling Al7075 using Response Surface Methodology (RSM) found that increase cutting speed did not result in increase of $\mathrm{Fz}$ and $\mathrm{Mz}$ (Kyratsis et al. in Davim [12]), while increase feed rate and tool diameter would increase both forces in drilling. The difference result may due to difference material used. Another research on drilling on titanium using RSM design experiment shown that cutting force and feed rate both were significantly affecting thrust force and torque [13]. It is also evidence that cutting fluid does not play a role in affecting both forces. It may due to the method of applying coolant in this experiment - an external coolant supply - was not effective. The coolant could not reach the tool-chips interface therefore there was no different in forces whether drilling with or without coolant application. A compressive flood coolant application might help to reduce the forces during drilling as claimed by Rahim \& Sasahara [5]. There was a difference up to $1000 \mathrm{~N}$ of thrust force between MQL synthetic ester and flood coolant while torque difference up to 11 N.m.

An important note in interpreting of experimental analysis, if the percent contribution due to error (unknown and uncontrolled factors) is low, $15 \%$ or less, then it is assumed that no important factors were omitted from the experiments. If it is high value, $50 \%$ or more, then some important factors were definitely omitted, conditions were not precisely controlled, or measurement error was excessive [14]. In case of ANOVA result of thrust force, the error is $31 \%$, it means some factors that may influenced the thrust force are omitted from the experiments. However, the error is less than $50 \%$ or it is still acceptable. 
The next step is analysis to find the optimum forces that may works by varying the machining parameters. The $\mathrm{S} / \mathrm{N}$ ratio of Table 3.3 and 3.4 of both thrust and torque then being plotted as shown in Fig 3.3. Signal to noise ratio indicates how the controlled parameters (signal) affecting the measured result in compare to disturbance (noise or uncontrolled parameters). Therefore, the higher $\mathrm{S} / \mathrm{N}$ ratio is preferable. From Fig. 3.4 we can detect that the optimum thrust force would be achieved by choosing machining with coolant and the material being HT1 treated on drilling depth of $10 \mathrm{~mm}$, cutting speed of 27 $\mathrm{m} / \mathrm{min}$ and feed rate $0.08 \mathrm{mmm} / \mathrm{rev}$. While, minimum torque would be achieved when drilling without coolant, material as HT2, depth of drilling $45 \mathrm{~mm}$, cutting speed at $35 \mathrm{~m} / \mathrm{min}$ and feed rate of $0.08 \mathrm{~mm} / \mathrm{rev}$.

\section{a. Contribution of Paramaters on Thrust Force}

(Fz)

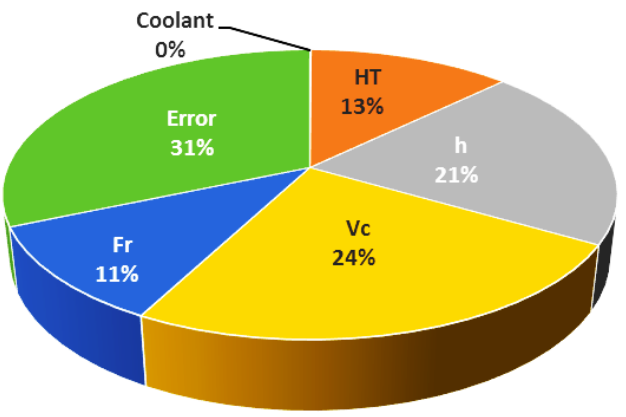

b. Contribution of Paramaters on Torque (Mz)

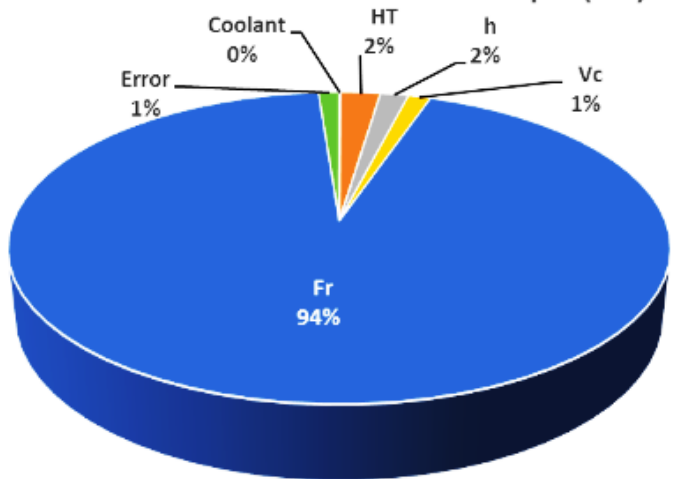

Fig. 3.3. Contribution of each factors to the thrust force (a) and to the torque (b)
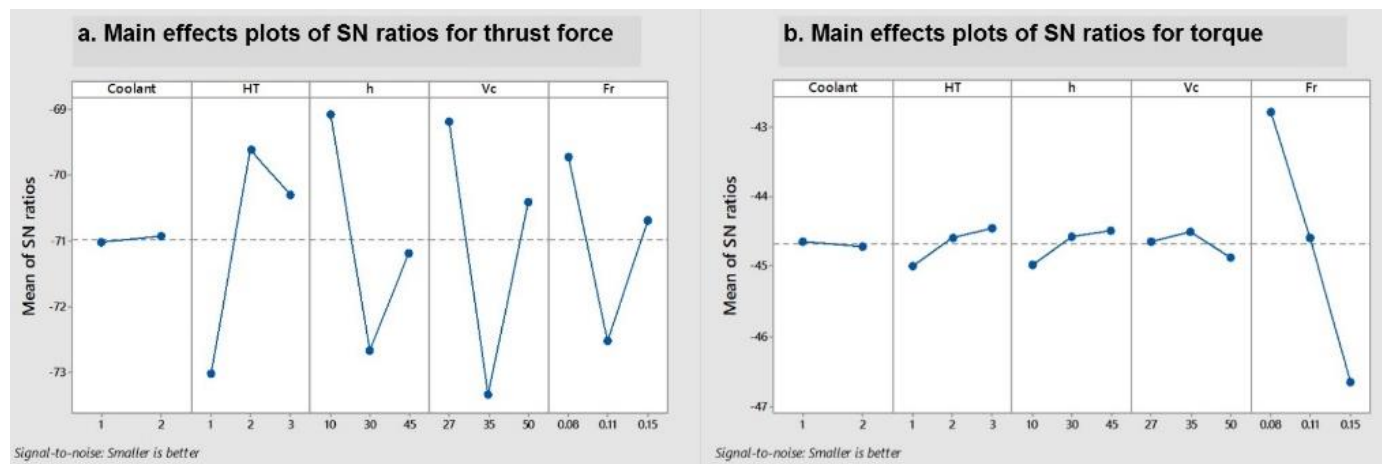

Fig. 3.4. Means of forces and S/N effect for each control factor; (a) thrust force, (b) torque. 
Both forces require different level of parameters in order to achieve their minimum values. Therefore, we should smartly decide which one we should choose. As mentioned previously that application of coolant would not change significantly to thrust and torque, together with environment consideration, the drilling without coolant may be chosen. Furthermore, as feed rate predominantly affecting the torque we may abandon the level of three other factors and follow the ones which result the minimum thrust force. Thus, optimum thrust force and torque may be achieved by applying $\mathrm{Vc}$ of $27 \mathrm{~m} / \mathrm{min}$, Fr of 0.08 $\mathrm{mm} / \mathrm{rev}$ on depth of $10 \mathrm{~mm}$ on material at HT1 without coolant.

\section{CONCLUSION}

Following the result and discussion, we may come to conclusion regarding drillability of Ti$6 \mathrm{Al}-2 \mathrm{Sn}-4 \mathrm{Zr}-6 \mathrm{Mo}$ from the forces point of view:

a. Among five parameters that varied: cutting speed, depth of drilling, heat treatment and feed rate influenced the thrust force by order in percentage as 24, 21, 13, and 11 respectively. While torque was greatly influenced by feed rate up to $94 \%$. Applying of coolant did not contribute in reducing the drilling forces.

b. The optimum drilling forces condition would be achieved when drilling with cutting speed of $27 \mathrm{~m} / \mathrm{min}$, feed rate of $0.08 \mathrm{~m} / \mathrm{rev}$ on depth of only $10 \mathrm{~mm}$ without coolant while material should be HT1 treated.

The further reduction in forces may be gained either by applying high pressure coolant or using the through coolant tool design.

\section{ACKNOWLEDGMENT}

We would like to thank Ministry of Research, Technology and Higher Education of Republic Indonesia through the DIKTI scholarship that financially supports the main author to pursue his $\mathrm{PhD}$ degree at the Auckland University of Technology. We would like also appreciate the Auckland University of Technology that support for the funding after third year passed.

\section{REFERENCES}

1. Zhang, P. F.; Churi, N. J.; Pei, Z. J.; and Treadwell, C. (2008). Mechanical drilling processes for titanium alloys: a literature review. Machining Science Technology, 12(4):417-444.

2. Pirtini, M.; and Lazoglu, I. (2005). Forces and hole quality in drilling. International Journal Machine Tools \& Manufacture, 45(11), 1271-1281.

3. Khanna, N; and Davim, J. P. (2015). Design-of-experiments application in machining titanium alloys for aerospace structural components. Measurement, 61, 280-290.

4. Rashid, R. A.; Sun, S.; Wang, G.; and Dargusch, M. S. (2012). An investigation of cutting forces and cutting temperatures during laser-assisted machining of the Ti-6Cr$5 \mathrm{Mo}-5 \mathrm{~V}-4 \mathrm{Al}$ beta titanium alloy. International Journal Machine Tools \& Manufacture, 63, 58-69.

5. Rahim, E. A.; and Sasahara, H. 2011. A study of the effect of palm oil as MQL lubricant on high speed drilling of titanium alloys. Tribology International, 44(3), 309-317.

6. Sharif, S.; Rahim, E. A.; and Sasahara, H. (2012). Machinability of Titanium Alloys in Drilling, Titanium Alloys - Towards Achieving Enhanced Properties for Diversified Applications, Nurul Amin, A. K. M. (Ed.), InTech.

7. Rahim, E.A.; Kamdani, K.; and Sharif, S. (2008). Performance Evaluation of Uncoated Carbide Tool in High Speed Drilling of Ti6Al4V. Journal of Advanced Mechanical Design, Systems, and Manufacturing, 2(4):522-531.

8. Lutjering, G.; and Williams, J. C. (2007). Titanium. 2nd ed. (Derby B, ed.). SpringerVerlag BerlinHeidelberg.

9. Youssef, Y. A.; Beauchamp Y. and Thomas, M. (1994). Comparison of a full factorial experiment to fractional and taguchi designs in a lathe dry turning operation. Computers \& Industrial Engineering, 27(1-4):59-62. 
10. Islam, M. N.; and Pramanik, A. (2016). Comparison of Design of Experiments via Traditional and Taguchi Method. Journal of Advanced Manufacturing Systems, 15(3):151-160.

11. Neto, N. F. M. (2017). Orbital drilling of Titanium alloys for aeronautics applications. Experimental studies. Master's Dessertation, Universidade Do Porto, Portugal.

12. Davim, J. P. (2016). Design of Experiments in Production Engineering. Springer International Publishing Switzerland.

13. Chatterjee, S.; Mahapatra, S. S.; and Abhishek, K. (2016). Simulation and optimization of machining parameters in drilling of titanium alloys. Simulation Modelling Practice and Theory, 62 (2016) 31-48.

14. Ross, P. J. (1988). Taguchi Method for Quality Engineering. Mc Graw Hill Company 